\title{
The Emerging MDMA Pandemic
}

\author{
Suprakash Chaudhury* and Swaleha Mujhawar \\ Department of Psychiatry, Dr. D. Y. Patil Medical College, India \\ *Corresponding author: Suprakash Chaudhury, Department of Psychiatry, Dr. D. Y. Patil Medical College, Pimpri, Pune-411018, India
}

Submission: 㭗 February 26, 2018; Published: 監 March 20, 2018

\section{Editorial}

A new wave of epidemic is emerging that is posing serious mental health risks to people all around the world. This epidemic is caused by a club or party drug 3,4-methylenedioxymethamphetamine (MDMA). MDMA is a psychoactive drug with stimulant and hallucinogenic properties first made in 1912 by the German pharmaceutical company Merck. It was found to improve psychotherapy beginning but later became popular as a street drug in the 1980s [1]. In the year 2017, between 9 and 29 million persons between the ages of 15 and 64 used MDMA i.e. $0.19 \%$ to $0.71 \%$ of the world population [2]. It is used primarily as a recreational drug associated with the "rave" culture and, as yet, has no accepted medical uses.

MDMA has become widely known as ecstasy (shortened "E", "X", or "XTC"), usually referring to its tablet form. The UK term "mandy" and the US term "molly" colloquially refer to MDMA in a crystalline powder form that is thought to be free of adulterants [3]. The experience elicited by MDMA depends on the dose, setting, and user [4]. In psychotherapeutic settings MDMA effects have been described by infantile ideas, alternating phases of mood, sometimes memories and moods connected with childhood experiences [5]. In a quiet environment and when concentrating, it is associated with increased lucidity, capability of concentration, sensitivity of aesthetic aspects of the background and emotions, as well as greater capability of communication with others [6]. The most serious short-term physical health risks of MDMA are hyperthermia and dehydration [7]. Acute toxicity is mainly caused by serotonin syndrome and sympathomimetic effects [8]. Impairments in multiple aspects of cognition, including attention, learning, memory, visual processing, and sleep have been found in regular MDMA users. Long-term exposure to MDMA produces marked neurodegeneration in striatal, hippocampal, prefrontal, and occipital serotonergic axon terminals by several interdependent mechanisms including excitotoxicity, mitochondrial damage and oxidative stress $[9,10]$. In utero exposure to MDMA is associated with a neuro- and cardiotoxicity and impaired motor functioning. Motor delays may be temporary during infancy or long-term. The severity of these developmental delays increases with heavier MDMA use [11].
Approximately $60 \%$ of MDMA users experience withdrawal symptoms when they stop taking MDMA. Some of these symptoms include fatigue, loss of appetite, depression, and trouble concentrating. Tolerance to some of the desired and adverse effects of MDMA is expected to occur with consistent MDMA use. Rarely MDMA abuse can result in death due to hyperthermia, hyponatremia, rhabdomyolysis and cardiovascular collapse [12]. Psychiatric symptoms associated with MDMA include flashbacks, rage, amnestic syndrome, panic attacks, depression, suicidal ideation, paranoid reaction and psychosis. A single dose has been reported to cause persistent psychosis [13]. Research in mice has shown that the developing brain is highly vulnerable to the damaging effects of MDMA and/or alcohol. Mice, exposed to these drugs in a binge pattern during adolescence, show impaired memory and learning in adulthood [14].

MDMA is illegal in most countries [15]. Limited exceptions are sometimes made for research [3]. Researchers are investigating whether a few low doses of MDMA may assist in treating severe, treatment-resistant posttraumatic stress disorder (PTSD) [16]. MDMA produces clinical effects through serotonine (5-HT)1A, 5-HT1B, 5-HT2A, dopamine and alpha-2 receptors, along with oxytocin release, which improves bonding and raises levels of empathy. It enhances the quality of social interactions and thereby improves relationships thereby facilitating psychotherapy. However, it must be emphasized that the medical use involves moderate, infrequent doses of MDMA under medical supervision. In contrast to this, the recreational use involves high and frequent use of the drug, the possibility of adulterants and the concomitant use of other drugs-especially alcohol, cannabis, amphetamine and cocaine [1].

This drug of abuse continues to plague teens and young adults. We need to remain vigilant about patterns and trends of drug abuse. MDMA and the other "club drugs" are not benign. Their effects target the brain, alter neurochemistry, and possibly cause irreversible structural damage. Effective education and timely intervention may prevent these addictive drugs from becoming a way of life, a lifestyle that may have a literal "dead end." 


\section{References}

1. Sessa B, Nutt D (2015) Making a medicine out of MDMA. Br J Psychiatry 206(1): 4-6.

2. (2017) United Nations office on drugs and crime. World Drug Report United Nations Publications, Vienna.

3. (2016) National Institute on Drug Abuse. Drug Facts: MDMA (Ecstasy or Molly). National Institutes of Health; US Department of Health and Human Services.

4. Betzler F, Viohl L, Seiferth NR, Foxe J (2016) Decision-making in chronic ecstasy users: a systematic review. European Journal of Neuroscience 45(1): 34-44.

5. Baggott MJ, Kirkpatrick MG, Bedi G, de Wit H (2015) Intimate insight: MDMA changes how people talk about significant others. J Psychopharmacol 29(6): 669-677.

6. Carvalho M, Carmo H, Costa VM, Capela JP, Pontes H, et al. (2012) Toxicity of amphetamines: an update. Arch Toxicol 86(8): 1167-1231.

7. Greene SL, Kerr F, Braitberg G (2008) Review article: amphetamines and related drugs of abuse. Emerg Med Australas 20(5): 391-402.

8. Steinkellner T, Freissmuth M, Sitte HH, Montgomery T (2011) The ugly side of amphetamines: short- and long-term toxicity of 3,4-methylenedioxymethamphetamine (MDMA, 'Ecstasy'), methamphetamine and d-amphetamine. Biol Chem 392(1-2): 103-115.

9. Garg A, Kapoor S, Goel M, Chopra S, Chopra M, et al. (2015) Functional
Magnetic Resonance Imaging in Abstinent MDMA users: A Review. Curr Drug Abuse Rev 8(1): 15-25.

10. Halpin LE, Collins SA, Yamamoto BK (2014) Neurotoxicity of methamphetamine and 3,4-methylenedioxy meth- amphetamine. Life Sci 97(1): 37-44.

11. Singer LT, Moore DG, Fulton S, Goodwin J, Turner JJ, et al. (2012) Neurobehavioral outcomes of infants exposed to MDMA (Ecstasy) and other recreational drugs during pregnancy. Neurotoxicol Teratol 34(3): 303-310.

12. Hall AP, Henry JA (2006) Acute toxic effects of 'Ecstasy' (MDMA) and related compounds, overview of pathophysiology and clinical management. Br J Anaesth 96(6): 678-685.

13. Patel A, Moreland T, Haq F, Siddiqui F, Mikul M, et al. (2011) Persistent psychosis after a single ingestion of "Ecstasy" (MDMA). Prim care companion CNS Disord 13(6): PCC.11101200.

14. Infer VA, Aguilar MA, Miñarro J, Arias RM (2012) Effect of intermittent exposure to ethanol and MDMA during adolescence on learning and memory in adult mice. Behav Brain Funct 8: 32

15.Vikram P (2010) Mental and neurological public health. A global perspective. San Diego: Academic Press/Elsevier, ( $1^{\text {st }}$ edn), Netherlands, p. 57.

16. Amoroso T, Workman M (2016) Treating posttraumatic stress disorder with MDMA-assisted psychotherapy: A preliminary meta-analysis and comparison to prolonged exposure therapy. J Psychopharmacol 30(7): $595-600$.

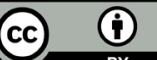

Creative Commons Attribution 4.0 International License

For possible submissions Click Here

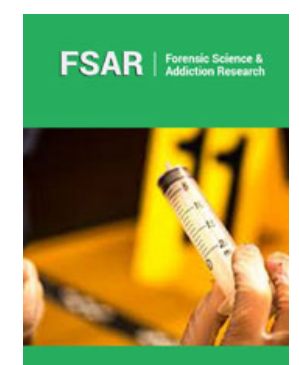

\section{Forensic Science \& Addiction Research}

Benefits of Publishing with us

- High-level peer review and editorial services

- Freely accessible online immediately upon publication

- Authors retain the copyright to their work

- Licensing it under a Creative Commons license

- Visibility through different online platforms 